D.O.I.: $10.3895 / \mathrm{S} 1808-04482011000400008$

\title{
PROPOSIÇÃO DE UM MODELO CONCEITUAL EM TORNO DA PRÁTICA DA GOVERNANÇA EM CADEIAS LOGÍSTICO-PORTUÁRIAS
}

\section{CONCEPTUAL MODEL PROPOSITION ABOUT THE PORT LOGISTICS CHAIN GOVERNANCE}

\author{
Gabriel Sperandio Milan ${ }^{1}$; Guilherme Bergmann Borges Vieira ${ }^{2}$ \\ ${ }^{1}$ Universidade de Caxias do Sul - UCS - Caxias do Sul - RS - Brasil \\ gsmilan@ucs.br \\ ${ }^{2}$ Universidade de Caxias do Sul - UCS - Caxias do Sul - RS - Brasil \\ gbvieira@cpovo.net
}

\begin{abstract}
Resumo
Os processos de importação e de exportação são extremamente dinâmicos e as empresas que se envolvem com eles devem buscar, constantemente, a melhor relação entre os custos e o nível de serviço logístico, com vistas a gerarem ofertas de maior valor ao mercado. Neste contexto, a eficiência portuária é de fundamental importância para o aumento da competitividade dos diferentes setores exportadores de um país, impactando na economia como um todo. A concepção moderna de gestão portuária deve considerar não apenas o porto em si, mas o contexto de toda a comunidade portuária, ou seja, o conjunto de atores que realizam atividades direta ou indiretamente associadas ao porto. Além disso, deve-se buscar o alinhamento e a coordenação destes atores, para que assim o porto exerça um papel de indução da competitividade regional. Diante desse cenário, o presente trabalho teve como objetivo propor um modelo conceitual para apoiar o estudo da governança em cadeias logístico-portuárias. Com o estudo de caso do Porto de Valência, foi possível elaborar um modelo abrangente e consistente, que sintetiza as principais ações de governança desenvolvidas no referido porto, as quais permitiram seu reconhecimento como Best-in-Class no setor. A partir da aplicação desse modelo, será possível identificar iniciativas ou direcionamentos para o desenvolvimento de cadeias logístico-portuárias no Brasil e, consequentemente, gerar um aumento da competitividade brasileira no contexto global.
\end{abstract}

Palavras-chave: governança, cadeias logístico-portuárias, competitividade.

\section{Introdução}

Como consequência do processo de globalização, as relações comerciais internacionais se intensificaram. Segundo a OMC - Organização Mundial do Comércio, o crescimento das exportações mundiais no período de 1950 a 2009 foi, em média, 1,7 vezes superior ao crescimento econômico. O ápice do índice ocorreu nos anos noventa, havendo um arrefecimento do mesmo na última década, especialmente devido à redução da taxa de crescimento das exportações $(3,2 \%)$, número bem inferior à média do período $(5,8 \%)$. De qualquer modo, o crescimento do comércio 
mundial, apresentado através das exportações, foi sempre superior ao crescimento econômico mundial (OMC, 2010).

Esse crescimento do intercâmbio comercial aumenta a demanda por serviços atinentes ao comércio exterior, com intensificação da concorrência entre as empresas. Neste contexto, para os prestadores de serviço na área do comércio internacional, identificar antecipadamente mudanças no mercado mundial e prever seus impactos garante, de certa forma, uma possível vantagem competitiva. Processos de importação e de exportação são extremamente dinâmicos e as empresas que se relacionam com eles devem buscar, constantemente, a redução em seus custos e alternativas que viabilizem novas opções de escolha no mercado. Isso está diretamente associado, entre outros fatores, à estratégia logística adotada. As atividades que compõem a logística, segundo Hesse e Rodrigue (2004), podem ser classificadas em duas funções principais: distribuição física e gestão de materiais. A distribuição física é o termo que engloba todo o conjunto de atividades de movimentação de materiais dos pontos de produção aos pontos de venda e consumo (MCKINNON, 1988 apud HESSE; RODRIGUE, 2004). Já a gestão de materiais considera todas as atividades relacionadas à manufatura nos diferentes estágios relacionados à cadeia de suprimentos, incluindo planejamento da produção, previsão de demanda, compras e gestão de estoques (HESSE; RODRIGUE, 2004).

Quando os fornecedores e clientes estão localizados em diferentes países, estão sendo executadas atividades de Distribuição Física Internacional (DFI) e parte dessas atividades (ou fluxos) estão diretamente relacionadas com os portos, tanto de embarque como de destino, sendo, portanto, consideradas fluxos logístico-portuários.

Tais fluxos, que podem ser físicos, financeiros e de informação (BEAMON, 1998), tem impacto na competitividade dos setores exportadores e importadores que se utilizam do porto, influenciando tanto o custo dos produtos como os níveis de serviço aos clientes - velocidade e confiabilidade com que um item pedido torna-se disponível (HESKETT, 1994). A qualidade com que tais fluxos são gerenciados e, conseqüentemente, os custos decorrentes dos mesmos dependem do grau de coordenação existente entre os distintos atores que formam parte da cadeia logísticoportuária. E é nesse ponto que entra a governança, cujo conceito tem relação com as práticas de coordenação de atividades através de redes (HIRST, 2000). Segundo Arbage (2004), a literatura não diferencia claramente os conceitos de governança e coordenação, tratando-os, na maioria das vezes, como sinônimos. No entanto, segundo o autor, é possível diferenciar conceitualmente a coordenação, os mecanismos de coordenação e a estrutura de governança. Geiger (2010), por sua vez, diferencia os conceitos de estrutura de governança e ações de governança. Estas últimas estão relacionadas com os mecanismos indutores de coordenação entre os atores, e no contexto do presente estudo foram parte do que denominou-se prática da governança. No caso portuário, o nível 
de serviços e os custos (resultado final do processo) estão relacionados à atuação de uma série de atores, os quais precisam ser efetivamente coordenados por meio de ações de governança, o que justifica a proposição de um modelo conceitual em torno da prática da governança em cadeias logístico-portuárias, finalidade do presente estudo.

Diante desse cenário, o presente trabalho tem como objetivo geral propor um modelo conceitual que apóie o estudo da prática governança em cadeias logístico-portuárias para que, a partir da efetiva utilização desse modelo, seja possível estabelecer iniciativas ou direcionamentos para o desenvolvimento do setor no Brasil, repercutindo no aumento da competitividade brasileira. Para tanto, tomou-se como referência para a elaboração do modelo conceitual as boas práticas existentes no contexto internacional, mais especificamente, no Porto de Valência - Espanha.

Além disso, foram estabelecidos os seguintes objetivos específicos: (i) identificar os principais fatores responsáveis pelo nível de excelência da cadeia logístico-portuária de Valência (Espanha); (ii) identificar as principais dimensões associadas aos fatores identificados; (iii) analisar criticamente as diferentes dimensões e seus respectivos fatores, visando reduzir lacunas e redundâncias; e (iv) propor um modelo de avaliação da governança em cadeias logístico-portuárias, tendo como base os objetivos anteriores. A escolha por Valência como referência para a elaboração do modelo conceitual deve-se ao fato de o mesmo ter sido considerado Best-in-Class em clusters portuários pelo Port Cluster Governance Committee (PCGC) do Global Institute of Logistics (GLI).

O processo de avaliação para tal reconhecimento deu-se em diversas etapas, baseando-se em dados secundários, informações de especialistas, entrevistas e visitas in loco nos clusters portuários avaliados. O porto de Valência foi escolhido pelo desenvolvimento e grau de maturidade de seu sistema de garantia da qualidade para o cluster portuário, denominado "Marca de Garantia" (LÓPEZ; POOLE, 1998); por apresentar uma cadeia logístico-portuária comprometida e efetivamente integrada; por seus sistemas de informação, os quais impulsionam a integração e coordenação dos atores da comunidade portuária; pela liderança da Autoridade Portuária de Valência e seu braço de pesquisa, Fundación Valenciaport, no processo de coordenação da comunidade portuária e pelas boas relações porto-cidade evidenciadas em Valência. Além disso, assim como o Porto de Santos, Valência caracteriza-se como um "centro de cargas" (DE LANGEN; van der LUGT; JOOST, 2002) e seus terminais de contêineres possuem volumes de movimentação de cargas comparáveis aos de Santos.

Cabe comentar que o processo de globalização da economia mundial coloca os países diante de duas situações que, apesar de conflitantes, se bem geridas, podem permitir a obtenção de possíveis vantagens competitivas e resultar em aumento no bem-estar geral do país. O acirramento da concorrência, à primeira vista, apresenta risco ou incertezas em nível pessoal, empresarial e governamental, o que pode ser interpretado como uma ameaça. Por outro lado, também é possível 
perceber esse fator como uma oportunidade de melhorias, visando adaptar-se ao acelerado processo de mudanças no contexto global e alcançar um novo patamar de competitividade. Diante disso, o mais razoável é tentar minimizar as ameaças existentes, utilizando todos os recursos disponíveis, e procurar explorar as oportunidades que emergem no mercado que, embora visíveis, muitas vezes são ignoradas.

Disponibilizar um produto ao mercado global significa mais do que simplesmente considerar e agir sobre os diferentes aspectos do mesmo, tais como características físicas (features), canais de distribuição, preço e promoção (divulgação) (KOTLER; KELLER, 2006). É necessário pensar nos serviços agregados e, entre tais serviços, na logística de distribuição, que engloba todos os caminhos percorridos deste os locais iniciais de fornecimento até os pontos finais de consumo no mercado externo (BOWERSOX; CLOSS, 2001; DORNIER et al., 2000). Portanto, é de fundamental importância a avaliação da prática da governança em cadeias logístico-portuárias portuários, pois a mesma pode facilitar ou dificultar as estratégias e as respectivas ações para agilizar as exportações e as importações, reduzindo custos desnecessários e agregando valor à economia brasileira.

Entre os benefícios que podem ser alcançados por meio de melhores práticas de governança em cadeias logístico-portuárias, e que justificam a importância do modelo conceitual proposto, é possível citar os seguintes: (i) permitir um melhor alinhamento entre os diferentes atores da comunidade portuária; (ii) melhorar a infra-estrutura e a gestão de transportes; (iii) melhorar a eficácia e a eficiência dos portos brasileiros, bem como sua competitividade na cadeia logística internacional; (iv) simplificar procedimentos administrativos e reduzir o tempo de execução dos mesmos; (v) melhorar a qualidade dos serviços prestados aos usuários; (vi) melhorar a consistência das informações trocadas entre os diferentes atores nacionais e internacionais; (vii) melhorar a rastreabilidade das transações comerciais; e (viii) fornecer informações consistentes e confiáveis para auxiliar no processo de tomada de decisões e no planejamento de novas exigências (ESPO, 2008).

\section{Referencial teórico}

\subsection{O setor portuário}

Em termos de extensão, pelo tipo de atividades realizadas e a estrutura dos colaboradores, a indústria (setor) portuária teve sempre significativas repercussões econômicas e sociais nas regiões e nos complexos urbanos onde está estabelecida, contribuindo com o seu desenvolvimento e com a geração de riquezas. Os portos, embora tenham evoluído nos seus vários estágios de simples pontos de carga e descarga dos bens a complexos industriais com infra-estrutura física compatível a um hub (ponto de concentração) da cadeia de transporte, continuam a evoluir conforme o meio 
ambiente de operação.

Atualmente, os portos são organizados em plataformas logísticas, agindo como interfaces entre o sistema de produção e os centros de consumo, atuando com a finalidade de eliminar a descontinuidade entre o modal marítimo e o transporte terrestre. Ao mesmo tempo, os portos estão se transformando em um componente estratégico para a atuação dos principais protagonistas da comunidade portuária, que inclui, entre outros, as autoridades portuárias, os operadores de terminais e os agentes de carga. Isto porque o porto passou a ser um elemento-chave na criação de redes para desenvolver e realizar as atividades de tais agentes (SUYKENS; van de VOORDE, 1998; MEERSMAN; MOGLIA; van de VOORDE, 1999; HEAVER et al., 2000; NOTTEBOOM; WINKELMANS, 2001; van de VOORDE; WINKELMANS, 2002; WINKELMANS, 2008).

O processo de planejamento portuário desempenha um papel-chave na determinação da posição de um porto na hierarquia marítima. Não se resume na identificação das áreas portuárias que necessitam ser desenvolvidas juntamente com os processos, mas sim é o instrumento que direciona a estratégia da expansão que define o próprio formato do porto no mercado global (FRANKEL, 1989; UNCTAD, 1993).

Uma das mudanças importantes que se tem identificado nos anos recentes é a expansão do porto além de seus limites históricos. Portanto, o ambiente não se restringe mais conforme o ritmo convencional e se estende além dos limites locais e das aproximações tradicionais (AKABANE; GONÇALVES; SILVA, 2008). De acordo com Akabane, Gonçalves e Silva (2008), o novo estilo do planejamento portuário não é mais baseado exclusivamente nas opiniões de especialistas em infra-estrutura, economistas, gestores de transporte e advogados. Requerem agora as recomendações de peritos ambientais, planejadores urbanos, consultores financeiros, especialistas em comunicação e profissionais de marketing. Claramente, a autoridade portuária do passado não pode mais dar respostas adequadas, devido às mudanças atuais em curso. É necessário, portanto, o exame de uma situação totalmente nova, em que a autoridade portuária terá a necessidade de negociar com outras entidades e instituições, estando mais vulnerável, em função de uma maior interferência externa e, consequentemente, menor independência (AKABANE; GONÇALVES; SILVA, 2008). É neste contexto que se deve considerar a governança portuária.

No Brasil, existem os seguintes tipos de instalações portuárias: (i) portos organizados, explorados pela União por meio das Companhias Docas ou mediante concessão; (ii) terminais portuários de uso privativo; (iii) estações de transbordo de carga; e (iv) instalações portuárias públicas de pequeno porte, essas três com exploração autorizada à iniciativa pública ou privada (ANTAQ, 2009). Segundo a ANTAQ (2009), quanto à regulamentação, o arcabouço legal básico que regulamenta o setor portuário é formado pela Constituição Federal de 1888, pela Lei Modernização dos Portos (Lei 8630/93) e pelas leis de criação da Agência Nacional de Transporte 
Aquiaviário (ANTAQ) e da Secretaria Especial de Portos (SEP).

Criada pela Lei $\mathrm{n}^{\circ} 10.233$, de 5 de junho de 2001, a ANTAQ é uma autarquia especial vinculada ao Ministério dos Transportes e à SEP que desempenha a função de entidade reguladora e fiscalizadora das atividades portuárias e de transporte aquaviário. Busca-se, a partir da agência reguladora, obter os seguintes resultados: estabelecimento de regras claras; previsibilidade das ações; equilíbrio na arbitragem de conflitos; garantia dos direitos de investidores; garantia de serviços adequados aos usuários; observância estrita aos preceitos legais; estímulo à concorrência; e fiscalização mais efetiva. Já a SEP, vinculada diretamente ao poder executivo, tem como objetivo definir políticas, diretrizes e investimentos públicos para o sistema portuário brasileiro.

De acordo com a ANTAQ (2009), um dos objetivos básicos do Plano Nacional de Logística e Transporte (PNLT), é a redução da participação do modal rodoviário na matriz de transporte brasileira, com o conseqüente aumento da participação dos demais modais, especialmente o aquaviário. Espera-se que esse modal cresça de 13\% em 2005 para 29\% em 2025. Isso se justifica por uma série de benefícios inerentes a esse modal, tais como: maior eficiência energética; grande capacidade de concentração de cargas; maior vida útil das infra-estruturas, equipamentos e veículos; segurança da carga; controle fiscal; menor consumo de combustível; emissão menor de poluentes (alterações climáticas e efeito estufa); redução do congestionamento de tráfego; menor custo da infra-estrutura; diminuição do número de acidentes; custo operacional inferior e menor impacto ambiental e emissão de ruídos. Para que tal objetivo seja factível é fundamental um sistema portuário eficiente, considerando não apenas o porto em si, mas a cadeia logístico-portuária como um todo.

É visível o crescimento da movimentação de cargas nos portos brasileiros nos últimos anos, (Tabela 1), apesar da ligeira queda em 2009, decorrente da crise global. Tal crescimento se verifica em todos os grupos de cargas (granéis líquidos, granéis sólidos e carga geral).

Tabela 1 - Movimentação de cargas nos portos brasileiros (em toneladas)

\begin{tabular}{c|c|c|c|c}
\hline Anos & Granel Sólido & Granel Líquido & Carga Geral & Total \\
\hline 2001 & 289.265 .117 & 163.986 .765 & 52.955 .002 & 506.206 .884 \\
2002 & 301.972 .374 & 163.135 .324 & 63.897 .353 & 529.005 .051 \\
2003 & 336.276 .308 & 161.886 .081 & 72.627 .666 & 570.790 .055 \\
2004 & 369.611 .250 & 166.555 .087 & 84.554 .208 & 620.720 .545 \\
2005 & 392.903 .932 & 163.717 .494 & 92.797 .355 & 649.418 .781 \\
2006 & 415.727 .739 & 175.541 .324 & 101.564 .405 & 692.833 .468 \\
2007 & 457.435 .373 & 194.598 .576 & 102.682 .706 & 754.716 .655 \\
2008 & 460.184 .343 & 195.637 .355 & 112.501 .852 & 768.323 .550 \\
2009 & 432.985 .386 & 197.934 .640 & 102.011 .115 & 732.931 .141 \\
\hline 2010 & 505.887 .090 & 208.457 .610 & 119.538 .097 & 833.882 .796 \\
\hline
\end{tabular}

Fonte: Anuário Estatístico Portuário (ANTAQ, 2010) 
Considerada a importância do setor, e visando acompanhar a dinâmica dos serviços portuários, notadamente em razão da demanda por esses serviços exercida pelo comércio exterior brasileiro, a ANTAQ mantém o Sistema Permanente de Acompanhamento dos Preços e do Desempenho Operacional dos Serviços Portuários - Desempenho Portuário.

Esse sistema objetiva produzir indicadores operacionais e estatísticos, com base em dados e informações recebidas das Administrações dos Portos Organizados e dos Terminais de Uso Privativo, associados às operações dos navios - carregamento e descarga - que operam em cada uma destas instalações portuárias. O relatório está estruturado em capítulos que abordam indicadores de desempenho portuário; indicadores de preços dos serviços portuários para contêineres, granéis sólidos e carga geral; utilização da mão-de-obra avulsa e própria nos portos organizados e terminais; acessos viários aos portos organizados nacionais e ranking de desempenho portuário. Apesar da relevância desse sistema, o mesmo é restrito a algumas operações portuárias, não abordando, portanto, a cadeia logístico-portuária como um todo, assunto oportuno no atual contexto brasileiro.

\subsection{A governança em cadeias logístico-portuárias}

De acordo com Geiger (2010), o estudo da governança em aglomerados empresariais apresenta duas abordagens predominantes: (i) ênfase na base territorial; e (ii) ênfase na sequência das atividades. O termo cluster normalmente está associado à primeira abordagem, sendo mais utilizado quando se fala em sequência de atividades o conceito de cadeia produtiva.

Especificamente na área portuária, para De Langen (2004), um cluster portuário consiste em todas as atividades relacionadas à chegada de navios e de cargas localizadas na região do porto. Trata-se, portanto, do conceito de comunidade portuária ampliada ao tecido econômico. Por meio dos diversos atores do cluster portuário (stakeholders), o conceito se estende também às perspectivas sociais e meio-ambientais. Nessa definição há uma clara orientação à sequência de atividades. Considera-se, portanto, mais adequada a utilização do conceito de "cadeia portuária" ao invés de cluster, uma vez que este último geralmente está associado à questão da territorialidade.

As atividades desenvolvidas no porto têm relação com uma série de outras atividades cujo alcance ultrapassa os limites territoriais do porto, iniciando nos locais de origem da carga, no caso da exportação, e terminando nos locais de destino, no caso da importação. Para fazer menção a essa abrangência, optou-se no presente estudo, sempre que possível, pela utilização do termo "cadeia logístico-portuária”. A Figura 1 apresenta as atividades logístico-portuárias na exportação e na importação. 
Figura 1 - Atividades logístico-portuárias na exportação e na importação

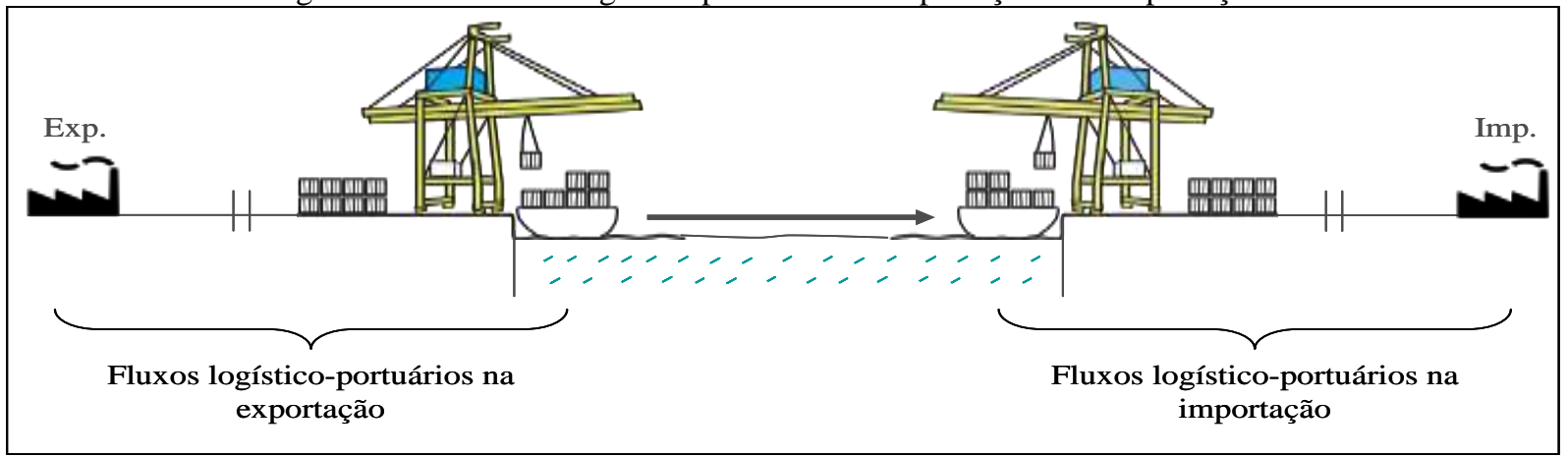

Fonte: Elaborada pelos autores

Na ótica de Winkelmans (2008), os diferentes atores (stakeholders) da cadeia logísticoportuária são todos os indivíduos ou grupos que têm interesse ou são afetados pelas atividades portuárias. Estes indivíduos ou grupos podem ser classificados em quatro categorias: (i) os stakeholders internos, que são os gestores do porto, os colaboradores do porto, os membros do conselho de administração e os shareholders; (ii) os players (atores) do mercado, que contemplam os órgãos de gestão de mão-de-obra avulsa, os operadores de transporte ferroviário, rodoviário e de cabotagem, as companhias de navegação e seus agentes, os freight forwarders (agentes internacionais de carga) e demais prestadores de serviços logísticos, os práticos, os rebocadores, os embarcadores e consignatários de cargas, etc.; (iii) a administração pública, que inclui os diferentes departamentos de governo em nível local, regional, nacional e supranacional; e (iv) a comunidade em geral (moradores do entorno portuário, consumidores, grupos de pressão ambiental, etc.).

O termo governança é utilizado para abordar os processos de tomada de decisão em assuntos de caráter coletivo. Basicamente, a governança se diferencia de outras aproximações conceituais que defendem que a tomada de decisão em contextos públicos pode ocorrer unilateralmente e mediante controle hierárquico. A noção de governança conta com uma ampla diversidade de conceitos. No entanto, no contexto desta pesquisa, a governança foi abordada como um sistema de regras formais e informais (normas, procedimentos, costumes), que estabelecem as pautas de interação entre atores no processo de tomada de decisão, considerando-se como atores relevantes tanto os poderes públicos quanto os atores sociais e econômicos envolvidos. A governança, portanto, trata-se de um novo estilo de governar, gerir de uma forma mais cooperativa, diferente do antigo modelo hierárquico em que as autoridades do estado ou, neste caso, as Autoridades Portuárias, exerciam o controle soberano sobre os grupos e os cidadãos. É uma maneira pela qual as instituições estatais, sociais e privadas participam e cooperam assiduamente na formulação e implantação de políticas (MAYNTZ, 2001).

Quanto ao conceito de governança corporativa, a OCDE - Organização para a Cooperação e Desenvolvimento Econômico (OCDE, 2004) a define como um sistema por meio do qual as corporações são direcionadas e controladas. A estrutura de governança corporativa especifica a 
distribuição de direitos e de responsabilidades entre os diferentes participantes da corporação, tais como conselho diretor, gerentes, shareholders e stakeholders, e dita as normas e procedimentos para o processo de tomada de decisão em relação aos assuntos corporativos. Dessa forma, é provida a estrutura por meio da qual os objetivos da corporação são estabelecidos, os meios para alcançar tais objetivos são definidos e as formas de aferição de performance são delineadas.

Segundo Brooks (2004), a governança deve ser considerada uma das prioridades da gestão portuária nos próximos anos. Essa idéia também é corroborada pela Conferência Européia de Portos Marítimos - The European Seaports Conference (ESPO, 2008), que decidiu estabelecer um comitê para tratar especificamente da governança portuária. Segundo o chairman da instituição, o Sr. Giuliano Gallanti, os desafios das constantes mudanças no ambiente logístico e na sociedade em geral requerem que os portos deixem de ser meros expectadores passivos e burocráticos. Ao invés disso, eles precisam ser coordenadores dinâmicos da comunidade portuária e agir como facilitadores da cadeia logística. E isso deve ser pensado não só nas relações com clientes, operadores de terminais, agentes logísticos e outros provedores de serviço. Devem ser consideradas, também, nas relações com os governos locais e regionais, com a sociedade e com todos os tipos de stakeholders.

Portanto, a governança portuária é um assunto atual e complexo em sua aplicação prática, sobretudo devido à diversidade de modelos de titularidade e gestão portuária existentes. Levando-se em conta o papel dos setores público e privado no desenvolvimento da infra-estrutura e superestrutura portuária e na prestação de serviços, são apresentados os modelos teóricos de gestão portuária apresentados na Figura 2.

Figura 2 - Modelos de gestão portuária

\begin{tabular}{|l|c|c|c|c|}
\hline \multirow{2}{*}{ Modelo } & \multicolumn{2}{|c|}{ Investimentos } & \multicolumn{2}{c|}{ Serviços } \\
\cline { 2 - 5 } & Infraestrutura & Superestrutura & Estiva & Outros \\
\hline Public Serviceport & Pública & Pública & Pública & Predominantemente públicos \\
\hline Toolport & Pública & Pública & Privada & Público-privados \\
\hline Landlord port & Público-privada & Privada & Privada & Público-privados \\
\hline Private Serviceport & Privada & Privada & Privada & Predominantemente privados \\
\hline
\end{tabular}

Fonte: Adaptado de Vieira (2003), Akabane, Gonçalves e Silva (2008) e Fundación Valenciaport (2009)

Obviamente, o modelo de governança se alterará significativamente conforme o modelo de titularidade e gestão portuária considerado. No modelo mais difundido (landlord port), o porto funciona como um coordenador geral e um gestor dos espaços, sendo os investimentos em infraestrutura (calado, linhas de atraque, sinalização marítima etc.) tanto públicos quanto privados, os investimentos em superestrutura (equipamentos de manipulação, veículos etc.) privados e os serviços predominantemente privados. À medida que o porto avança em sua tarefa de governança orientada a toda a cadeia logístico-portuária, tem-se o modelo portuário denominado recentemente de landlord avançado. A cadeia logístico-portuária compreende, de forma simplificada, os atores 
apresentados na Figura 3.

Figura 3 - Principais atores da comunidade portuária

\begin{tabular}{|l|l|l|}
\hline \multicolumn{1}{|c|}{ Mar } & \multicolumn{1}{|c|}{ Porto } & \multicolumn{1}{c|}{ Terra } \\
\hline Companhias Marítimas & Sep & Freight Forwarders \\
\hline Agentes Marítimos & Autoridades Portuárias & Despachantes Aduaneiros \\
\hline NVOCCS & Terminais de Contêineres & Exportadores E Importadores \\
\hline \multicolumn{2}{|c|}{ Fonte: Elaborada pelos autores }
\end{tabular}

As companhias marítimas ou armadores são as diferentes linhas regulares de navegação que escalam no porto. Os agentes marítimos são os representantes desses armadores (filiais ou empresas terceirizadas). Os Non Vessel Operating Common Carriers (NVOCCs) são os consolidadores de cargas marítimas, empresas que se dedicam ao agrupamento de pequenos lotes de mercadorias de pequenos embarcadores, buscando otimizar a ocupação do espaço de um contêiner (VIEIRA; RODRIGUES, 2005). Pode-se considerar que, enquanto os armadores estão mais voltados ao transporte de contêineres completos, denominados Full Container Loads (FCL), os NVOCCs dedicam-se ao transporte de cargas fracionadas, denominadas consolidadas ou Less than Container Loads (LCL).

Do lado da terra, os International Freight Forwarders (IFFs), também chamados no Brasil de agentes internacionais de carga (VIEIRA et al., 2007; VIEIRA; PASA; ARENHART, 2008), apresentam uma atuação mais ampla, uma vez que têm como especialidade prover uma variedade de funções que facilitam a movimentação de embarques internacionais (MURPHY; DALEY, 1997). Tais funções englobam tanto cargas FCL como LCL e incluem também serviços aduaneiros e de transporte terrestre, podendo chegar, em alguns casos, a projetos logísticos especiais que cobrem grande parte das necessidades dos clientes. Os despachantes aduaneiros, por sua vez, possuem um âmbito de atuação mais restrito, ocupando-se dos processos de liberação das cargas junto à Alfândega, tanto na exportação quando na importação. Os serviços dos despachantes, bem como os demais serviços logísticos, podem ser contratados, conforme o caso, pelos exportadores ou importadores, dependendo das condições de venda pactuadas entre os mesmos.

Nesse contexto, os portos devem se preocupar também com a aferição de sua performance para o efetivo controle de gestão e a consequente reorientação estratégica. Segundo Brooks e Pallis (2008), o modelo de governança é influenciado por fatores externos, relativos ao ambiente econômico, e por fatores internos, decisões de governança definidas pela própria autoridade portuária. Cabe ressaltar que os fatores internos, segundo os autores, podem ser agrupados em duas grandes categorias: estrutura e estratégia. A estrutura contempla aspectos como os processos desenvolvidos no porto e os sistemas internos que apóiam tais processos. Já a estratégia, refere-se aos fatores associados ao escopo dos serviços prestados e do mercado portuário (product-market scope) e ao plano estratégico em si. Todos esses fatores, internos e externos, que compõem o 
modelo de governança portuária são o input (entrada) do processo portuário como um todo, que tem como output (saída) o resultado ou a performance portuária. Tal performance pode ser avaliada por meio de indicadores de desempenho internos (eficiência) ou externos por parte dos stakeholders (eficácia).

Por conseguinte, a moderna gestão portuária deve estar orientada à governança da cadeia logístico-portuária. E o principal argumento para um envolvimento mais ativo da autoridade portuária na coordenação de tal cadeia é o fato de a eficiência na mesma não emergir espontaneamente, devido a vários fatores. Portanto, uma maior coordenação, fomentada pela autoridade portuária, pode levar a portos e cadeias logísticas mais eficientes (DE LANGEN; NIJDAM; van der HORST, 2007).

\section{Metodologia de pesquisa}

O presente estudo pode ser caracterizado como sendo qualitativo, de caráter exploratório, desenvolvido por meio de um estudo de caso (VERGARA, 2009; COOPER; SCHINDLER, 2003; YIN, 1994), que será tomado como base para a proposição de um modelo conceitual. Enquanto as técnicas quantitativas focam coisas que possam ser contadas, utilizando categorias predeterminadas que podem ser tratadas como dados internos ou ordinários e sujeitos à análise estatística, as técnicas qualitativas focam a experiência das pessoas e seu respectivo significado em relação a eventos, processos e estruturas, inseridos em cenários sociais (SKINNER; TAGG; HOLLOWAY, 2000).

A pesquisa qualitativa utiliza amostras pequenas e estatisticamente não-representativas, tendo por principais objetivos: ajudar a refinar conceitos, conhecer reações gerais, aprender a linguagem dos atores envolvidos ou explorar novas áreas de oportunidade (HELLEBUSCH, 2000). As metodologias qualitativas procuram explicar situações particulares e devem fornecer conclusões específicas para o caso ou os casos em estudo (HYDE, 2000).

A base para a generalização em estudos qualitativo-exploratórios é a analítica, proposta por Yin (1994), em que o objetivo do pesquisador deve ser o de expandir e generalizar teorias, e não o de estabelecer a frequência e a probabilidade nas quais um fenômeno pode ocorrer em determinada população (HYDE, 2000). Em estudos desse tipo comumente são utilizados levantamentos bibliográficos e documentais, entrevistas não padronizadas com pessoas que possuem prática com o problema de pesquisa, análise de exemplos que estimulem a compreensão e estudos de caso (GIL, 1999; MARCONI; LAKATOS, 2002). Neste contexto, e considerando os objetivos propostos para o estudo, foi estudado o caso do porto de Valência (Espanha), considerado Best-in-Class em clusters portuários pelo Port Cluster Governance Committee (PCGC) do Global Institute of Logistics (GLI), por meio de observação não participante e grupos de enfoque.

Tais grupos de enfoque foram desenvolvidos em Valência em novembro de 2009, no âmbito 
de um projeto denominado Proyecto GLIPORT: Estrategias para la Capacitación Portuária (DAVIU et al., 2010) e tiveram como público-alvo os profissionais responsáveis pelos seguintes setores considerados, pela Autoridade Portuária de Valência (Valenciaport), como propulsores da governança na cadeia logístico-portuária: (i) Pesquisa, Desenvolvimento e Inovação (PD\&I); (ii) Qualidade; (iii) Exploração e Gestão; (iv) Formação; e (v) Segurança, Meio-Ambiente e Responsabilidade Social.

As discussões geradas pelos grupos de enfoque foram gravadas em meio eletrônico e transcritas, para facilitar a posterior análise e interpretação dos resultados (RIBEIRO; MILAN, 2004; WOLCOTT, 1994), além de serem submetidas às técnicas de análise de conteúdo (BARDIN, 2004). Os resultados obtidos com a análise de conteúdo foram complementados por análise documental e por observação não participante (COOPER; SCHINDLER, 2003; VERGARA, 2009) na comunidade logístico-portuária estudada (Valência).

\section{Modelo conceitual proposto}

As principais ações desenvolvidas ou impulsionadas pela Autoridade Portuária de Valência, consideradas pontos-chave para o desenvolvimento do cadeia logístico-portuária da região, destacadas pelos grupos de enfoque e vinculadas às cinco áreas em análise foram as seguintes:

a) Exploração e Gestão Portuária: 1. realização de planejamento estratégico; 2. gestão econômico-financeira e coordenação, elaboração e controle orçamentário; 3. sistema de gestão por indicadores de desempenho (BSC - Balance Scorecard); 4. busca de novos tráfegos e relações com clientes; 5. estudos mercadológicos e identificação de oportunidades; 6. gestão da eficiência dos fluxos logísticos no porto (tempo); 7. gestão da eficiência dos fluxos logísticos entre os diferentes atores da comunidade portuária (tempo); e 8. redução dos custos operacionais no porto;

b) Formação de Mão-de-Obra: 1. atividades de formação na autoridade portuária; 2. atividades de formação para a comunidade portuária; 3. atividades de formação entre distintas comunidades portuárias; 4. atividades de cooperação e formação em nível internacional; e 5. desenvolvimento de uma mentalidade que favorece a geração de valor futuro e a inovação;

c) Qualidade: 1. estrutura de decisão na comunidade portuária; 2. relacionamento e interação entre os agentes da comunidade portuária; 3. manual de procedimentos logísticos e operações, englobando as atividades dos diferentes atores da comunidade portuária; e 4. procedimentos de garantia de qualidade para a comunidade portuária (Marca de Garantia);

d) Inovação: 1. liberação de saída e entrada de cargas sem papel (documentação física); 2. documentação eletrônica entre os diferentes atores; 3. follow-up das mercadorias na importação e na importação; 4. controle operacional e geração de indicadores; 5. objetivos integrados dos atores; 6. desenvolvimento de visão sistêmica entre os atores; 7. foro que favorece a discussão e a 
integração dos atores da comunidade (Sistema de Qualidade e Marca de Garantia); e 8. tomada de decisões comuns, orientada pela autoridade portuária;

e) Gestão Ambiental: 1. projetos de eficiência energética; 2. plano de segurança portuária segundo normas locais e internacionais; 3. avaliação dos riscos ambientais segundo padrões internacionais vigentes; 4. monitoramento do impacto ambiental; e 5. planos de investimento para a gestão ambiental portuária.

Analisando-se as ações listadas anteriormente, observa-se uma série de relações de causaefeito e uma série de sobreposições entre os fatores citados. Por exemplo: o sistema de qualidade do porto de Valência e a conseqüente marca de garantia da qualidade para a comunidade portuária (LÓPEZ; POOLE, 1998) é um fator citado por dois grupos de enfoque (inovação e qualidade), e relacionado com, pelo menos, três das cinco áreas em questão: inovação, qualidade e exploração e gestão portuário.

Dada essa situação, e visando gerar um modelo conceitual mais enxuto e consistente, as contribuições aportadas pelos distintos grupos foram organizadas em quatro áreas básicas e, tendo como base as ações desenvolvidas pela Autoridade Portuária de Valência, consideradas propulsoras da governança na comunidade portuária em questão, foram consideradas as ações associadas a cada área que configuram as boas práticas em Valência. Tais ações foram redigidas em forma de afirmativas, compondo um modelo composto pelas quatro áreas em questão (Formação e Gestão do Conhecimento, Gestão e Operações Portuárias, Qualidade dos Serviços e Alinhamento da Comunidade Portuária e Segurança, Responsabilidade Social e Gestão Ambiental) e oito afirmativas associadas a cada área, como segue:

I. Formação e Gestão do Conhecimento: 1. há uma nítida integração entre o porto e o meio acadêmico (universidades); 2. existe no porto um órgão responsável pela realização de atividades de formação na autoridade portuária em diferentes níveis; 3. são oferecidas e realizadas atividades de formação para toda a Autoridade Portuária; 4. são oferecidas e realizadas atividades de formação para toda a comunidade portuária (armadores, forwarders, despachantes aduaneiros, transportadores terrestres, exportadores e importadores, etc.); 5. as atividades de formação fomentadas pelo porto integram pessoas de distintas comunidades portuárias, relacionadas com outros portos; 6. são realizadas atividades de cooperação e formação em nível internacional; 7. a mentalidade dos funcionários do porto favorece a geração de valor futuro e a inovação; e 8. a mentalidade dos atores da comunidade portuária favorece a geração de valor futuro e a inovação no sistema portuário;

II. Gestão e Operações Portuárias: 1. existe um sistema de gestão estratégica, integrado e flexível, orientado por um conjunto equilibrado de indicadores de desempenho (BSC); 2. existe um 
sistema de gestão econômico-financeira estabelecido, o qual permite coordenar, elaborar e controlar o orçamento portuário; 3. existe uma estratégia comercial estabelecida e pró-ativa para a busca de novos tráfegos, cargas e relações com os clientes em nível nacional e internacional; 4. o porto desenvolve ativamente atividades de pesquisa, desenvolvimento e inovação, o que apóia seu posicionamento e permite a identificação de novas oportunidades comerciais; 5 . as infra-estruturas portuárias apresentam-se adequados para as operações atuais e seu crescimento futuro; 6. os fluxos logísticos no porto são eficientes em termos de tempo; 7. os fluxos logísticos entre os diferentes atores da comunidade portuária são eficientes em termos de tempo; e 8. os custos operacionais no porto são baixos e as tarifas são competitivas;

III. Qualidade dos Serviços e Alinhamento da Comunidade Portuária: 1. há no porto um sistema de informação comum aos atores da comunidade portuária que permitem a gestão e o controle fidedigno das operações. Esse sistema de informações permite aos usuários o follow-up das cargas na importação e na importação, o controle operacional e a geração de indicadores de desempenho; 2. as tarifas referentes ao conjunto dos serviços logísticos prestados pela comunidade portuária são claras, explícitas e uniformes entre os diferentes atores da comunidade; 3. o porto conhece as necessidades e expectativas dos clientes no que se refere ao serviço global relacionado à comunidade portuária e existe uma clara preocupação de melhoria dos fluxos logístico-portuários na exportação e na importação; 4. existe integração entre os diferentes atores da comunidade portuária, a qual é fomentada pelo porto; 5. existe uma estrutura estabelecida (foro, assembléia, conselho) que apóia o relacionamento, a interação entre os atores e a tomada de decisão para o aumento da qualidade e a resolução de problemas da comunidade portuária; 6. há um sistema de qualidade devidamente estabelecido e formalizado em um manual que inclui procedimentos logísticos e de operações que englobam as atividades dos diferentes atores da comunidade portuária; 7. a documentação é emitida, transmitida, apresentada e fiscalizada eletronicamente e o sistema de informação do porto permite a liberação de saída e entrada de mercadorias sem papel (documentação física); e 8. há compensações pecuniárias estabelecidas e efetivamente pagas em casos de descumprimento dos procedimentos de garantia de qualidade;

IV. Segurança, Responsabilidade Social Corporativa e Gestão Ambiental: 1. o porto avalia seus riscos ambientais segundo a legislação local e os padrões internacionais vigentes; 2. o porto possui planos de investimento para a gestão ambiental portuária; 3. o porto possui planos de contingência para acidentes ambientais, riscos e emergências, orientado pela legislação local e pelas normas internacionais vigentes; 4 . o porto faz monitoramento constante do impacto ambiental por ele causado (emissão de partículas, resíduos, consumo de água e energia, ruído e odores, impacto visual, etc.); 5. o porto tem projetos de eficiência energética e de sustentabilidade em andamento; 6. o porto desenvolve constantemente programas integrados de melhoria das condições de trabalho 
e da qualidade de vida, incluindo aspectos como prevenção à saúde física e mental (tais como combate à ansiedade, estresse), desenvolvimento de habilidades interpessoais, gestão de pessoas, etc.; 7. há uma boa integração porto-cidade e o porto desenvolve projetos sociais e comunitários; e 8. existe uma efetiva comunicação interna e externa da ações de responsabilidade social desenvolvidas em seus distintos âmbitos (laboral, social e ambiental) e voltadas à comunidade portuária.

Essas áreas e suas respectivas afirmativas são compreendidas pelo modelo conceitual proposto, o qual pode ser representado por meio de um losango, apresentado na Figura 4, que é formado por quatro eixos: I. Gestão e operações portuárias; II. Formação e gestão do conhecimento; III. Qualidade dos serviços e alinhamento da comunidade portuária e IV. Segurança, responsabilidade social e gestão ambiental.

Figura 4 - Modelo conceitual proposto

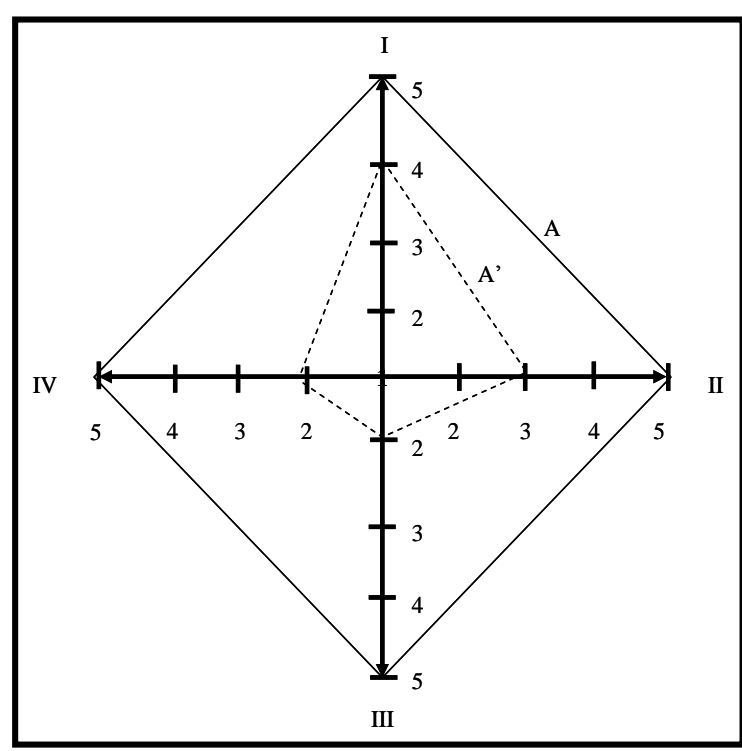

Fonte: Elaborada pelos autores

Cada eixo é composto pelas oito questões-chave referidas anteriormente. Assim sendo, o posicionamento de cada cadeia portuária que se queira analisar pode ser avaliado por meio dessas questões, as quais representam as boas práticas de governança na cadeia logístico-portuária obtidas por meio da análise do caso de Valência. A avaliação pode ser feita por meio de uma escala do tipo Likert de cinco pontos (1. Discordo Totalmente a 5. Concordo Totalmente).

Em cada eixo, a situação ideal seria configurada pela pontuação máxima (5), conforme escala sugerida, gerando uma área máxima que corresponde ao próprio losango (A). Já a pontuação mínima seria (1), ponto de origem de cada um dos quatro eixos propostos. A união dos pontos alcançados em cada eixo configuraria um polígono (A'). Assim sendo, a situação de cada cadeia logístico portuária no que se refere à governança seria dada pela área do polígono formado pela união dos diferentes pontos nos quatro eixos (A'), de forma similar ao modelo proposto por Santos 
et al. (2008). A diferença é que, no modelo de avaliação da estratégia de produção proposto pelos autores, eram considerados três eixos (conexão vertical, conexão horizontal e conexão externa), enquanto neste modelo são considerados quatro eixos (I. Gestão e Operações Portuárias; II. Formação e Gestão do Conhecimento; III. Qualidade dos Serviços e Alinhamento da Comunidade Portuária e IV. Segurança, Responsabilidade Social e Gestão Ambiental). Além disso, no trabalho de Santos et al. (2008), o número de questões associadas variava de eixo para eixo, sendo necessário um ajuste matemático para que fosse possível uma comparação. Já no presente modelo isso não será necessário, uma vez que se trata de oito afirmativas para cada um dos eixos.

Para a aplicação do modelo, deve-se selecionar uma amostra que represente de maneira adequada os diferentes atores das cadeias logístico-portuárias. No caso brasileiro, por exemplo, poderiam ser entrevistados os atores pertencentes aos Conselhos de Autoridade Portuária (CAPs) de cada porto, conforme composição descrita a seguir:

a) Poder Público: um representante do Governo Federal, que é o Presidente do Conselho, um representante do Governo do Estado, onde se localiza o porto e um representante dos municípios onde se localiza o porto ou os portos organizados abrangidos pela concessão;

b) Operadores Portuários: um representante da administração do porto, um representante dos armadores, um representante dos titulares de instalações portuárias privadas localizadas dentro dos limites da área do porto e um representante dos demais operadores portuários;

c) Classe dos Trabalhadores Portuários: dois representantes dos trabalhadores portuários avulsos e dois representantes dos demais trabalhadores portuários;

d) Usuários dos Serviços Portuários e Afins: dois representantes dos exportadores e importadores de mercadorias, dois representantes dos proprietários e consignatários de mercadorias e um representante dos terminais retroportuários.

No caso de outras cadeias logístico-portuárias, por sua vez, seriam entrevistados os representantes análogos aos dos informantes-chave entrevistados no caso brasileiro, indicados pelas Autoridades Portuárias em questão.

\section{Considerações finais}

O presente trabalho teve como objetivo central propor um modelo conceitual que auxilie o estudo da governança em cadeias logístico-portuárias (vide Figura 4) para que, a partir da aplicação desse modelo, seja possível identificar iniciativas ou direcionamentos para o desenvolvimento de cadeias logístico-portuárias no Brasil que, consequentemente, apóiem a competitividade dos setores exportadores brasileiros no contexto global.

Com o estudo de caso do Porto de Valência, foi possível elaborar um modelo abrangente e consistente, que sintetiza as principais ações de governança desenvolvidas no referido porto, as 
quais permitiram o seu reconhecimento como Best-in-Class no setor, em âmbito mundial.

Sendo assim, sugere-se a aplicação inicial do instrumento aos diferentes atores relacionados com a movimentação de cargas conteneirizadas nos portos brasileiros, especialmente nas cadeias logístico-portuárias com maior representatividade em termos de movimentação de contêineres, tais como Santos (SP), Itajaí (SC) e Rio Grande (RS), e seu posterior ajuste e refinamento.

A partir dos resultados obtidos, poderão ser estabelecidos e acompanhados indicadores de governança para as cadeias logístico-portuárias como um todo. Tais indicadores de desempenho poderão somar-se aos já utilizados pela ANTAQ e pela SEP para avaliar o desempenho dos portos brasileiros.

\begin{abstract}
The importing and exporting process are extremely dynamic and the companies that engage to them should seek constantly to better the relationship between cost and level of logistics services, in order to generate higher market value. In this context, the port efficiency is crucial for enhancing competitiveness of exporters in different sectors of a country, impacting the economy as a whole. The modern concept of port management must consider not only the port itself, but the context of the entire port community, namely the group of actors who perform activities directly or indirectly related to the port. In addition, you should seek alignment and coordination of these actors, so that the port carries the role of induction of regional competitiveness. Against this backdrop, this study aims to propose a conceptual model that supports the study of governance and port logistic chains. With the case study of the Port of Valencia, it was possible to develop a comprehensive e consistent model, summarizing the key governance actions undertaken in the port, which allowed its recognition as Best-in-Class in the sector. From the application of this model, it is possible to identify initiatives or directions for the development of port logistic chains in Brazil and consequently generate an increase Brazil's competitiveness in the global context.
\end{abstract}

Key-words: governance, port logistic chains, competitiveness.

\title{
Referências
}

AKABANE, G. K.; GONÇALVES, M. A.; SILVA, T. R. A importância do modelo de autoridade portuária como opção no planejamento logístico: uma pesquisa exploratória. In: VIEIRA, G. B. B.; SANTOS, C. H. S. (org.). Logística e gestão portuária: uma visão ibero-americana. Caxias do Sul: Educs, 2008. p. 49-61.

ARBAGE, A. P. Custos de transação e seu impacto na formação e gestão da cadeia de suprimentos: estudo de caso em estruturas de governança híbridas do sistema agroalimentar no Rio Grande do Sul. 2004. Tese (Doutorado em Administração) - Programa de Pós-Graduação em Administração - PPGA, Universidade Federal do Rio Grande do Sul (UFRGS), Porto Alegre, $2004 . \quad$ Disponível <http://www.lume.ufrgs.br/bitstream/handle/10183/4871/000416579.pdf?sequence=1>. Acesso em: 24 nov. 2011 .

BARDIN, L. Análise de conteúdo. Lisboa: Edições 70, 2004.

BEAMON, B. Supply chain design and analysis: Models and methods. International Journal of Production Economics, v. 55, n. 3, p. 281-294, 1998.

cross ref

BOWERSOX, D. J.; CLOSS, D. J. Logística empresarial: o processo de integração da cadeia de suprimento. São Paulo: Atlas, 2001. 
ANTAQ - Agência Nacional de Transporte Aquiaviário. Anuário Estatístico Portuário 2009. Disponível em: <http://www.antaq.gov.br/portal/Anuarios/Portuario2009/Index.htm>. Acesso em: 29 jul. 2010.

ANTAQ - Agência Nacional de Transporte Aquiaviário. Visão da ANTAQ sobre a logística portuária e hidroviária. Fernando Antonio Brito Fialho (Diretor Geral). Apresentação para o Grupo Votorantim. Brasília, 5 de maio de 2009. Disponível em: <http://www.antaq.gov.br/Portal/pdf/palestras/Mai09DGFialhoVotorantim.pdf>. Acesso em: 29 jul. 2010.

BROOKS, M. R. The governance structure of ports. Review of Network Economics, v. 3, n. 2, p. 168-183, 2004. cross ${ }^{\text {ref }}$

BROOKS, M. R.; PALLIS, A. A. Assessing port governance models: process and performance components. Maritime Policy \& Management: The Flagship Journal of International Shipping and Port Research, v. 35, n. 4, p. 411-432, 2008.

COOPER, D. R.; SCHINDLER, P. S. Métodos de pesquisa em administração. 7. ed. São Paulo: Bookman, 2003.

DAVIU, A. R. et al.. Documento de conclusiones del proyecto GLIPORT: estrategias para la capacitación portuaria. Revista de la Red de Expertos Iberoamericanos en Gestión Portuaria (REI), v. 1., n. 4, p.17-19, 2010.

DE LANGEN, P. W. Governance in seaport clusters. Journal of Maritime Economics and Logistics, v. 6, n. 4, p. $141-156,2004$.

cross

DE LANGEN, P. W.; NIJDAM, M. N.; Van Der HORST, M. R. Port performance indicators in ports. Journal of Maritime Research, v. 4, n. 1, p.23-36, 2007.

DE LANGEN, P. W.; Van Der LUGT, L. M.; JOOST H. A. A stylised container port hierarchy: a theoretical and empirical exploration. International Association of Maritime Economists. IAME Panama 2002 Conference. Proceedings... $\quad$ Panama City, $2002 . \quad$ Disponível em: <http://www.cepal.org/usi/perfil/iame_papers/proceedings/Langen_et_al.doc>. Acesso em: 24 nov. 2011.

DORNIER, P. et.. Logística e operações globais - texto e casos. São Paulo: Atlas, 2000.

ESPO - European Sea Ports Organisation. Annual Report 2007-2008. Brussels: ESPO, 2008. Disponível em: <http://www.espo.be/downloads/archive/8bf1fded-66f6-4e0f-8204-7e52754b9b69.pdf>. Acesso em: 13 abr. 2010.

FRANKEL, E. G. Strategic planning applied to shipping and ports. Maritime Policy and Management, n. 16, p. 123$132,1989$.

cross ret

FUNDACIÓN VALENCIAPORT. Valenciaport. Disponível em: 〈http://www.fundacion.valenciaport.com>. Acesso em: 10 mar. 2009.

GEIGER, A. Modelo de governança para apoiar a inserção competitiva de arranjos produtivos locais em cadeias globais de valor. Tese (Doutorado em Engenharia de Produção) - Programa de Pós-Graduação em Engenharia de Produção (PPGEP), Universidade Federal do Rio Grande do Sul (UFRGS), Porto Alegre, 2010.

GIL, A. C. Métodos e técnicas de pesquisa social. 5. ed. São Paulo: Atlas, 1999.

HEAVER, T. D. et al.. Do mergers and alliances influence European shipping and port competition? Maritime Policy and Management, n. 27, p. 363-373, 2000.

cross ref

HELLEBUSCH, S. Don’t read research by the numbers. Marketing News, v. 34, n. 19, p. 25, 2000.

HESKETT, J. L. Controlling Customer Logistics Service. International Journal of Physical Distribution and Logistics Management, v. 24, n. 4, 1994. 
HESSE, M.; RODRIGUE, J. P. The transport geography of logistics and freight distribution. Journal of Transport Geography, n. 12, p. 171-184, 2004.

cross ${ }^{\text {ref }}$

HIRST, P. Democracy and governance. In: Jon Pierre (ed.). Debating governance: authority, steering and democracy. Oxford University Press: New York, p. 13-35, 2000.

HYDE, K. F. Recognizing deductive processes in qualitative research. Qualitative Market Research, v. 3, n. 2, p. 82$89,2000$.

cross ref

KOTLER, P.; KELLER, K. L. Administração de marketing. 12. ed. São Paulo: Prentice Hall, 2006.

LÓPEZ, R. C.; POOLE, N. Quality assurance in the maritime port logistics chain: the case of Valencia, Spain. Supply Chain Management, v. 3, n. 1, p. 33-44, 1998.

cross ${ }^{\text {ref }}$

MARCONI, M. A.; LAKATOS, E. M. Técnicas de pesquisa: planejamento e execução de pesquisas, elaboração, análise e interpretação de dados. 5. ed. São Paulo: Atlas, 2002.

MAYNTZ, R. El estado y la sociedad civil en la gobernanza moderna. Revista del CLAD Reforma y Democracia, n. 21, p. 7-22, 2001.

MEERSMAN, H; MOGLIA, F.; Van Der VOORDE, E. Mergers and alliances in liner shipping: what do European port authorities have to fear? In: Halifax Conference. Proceedings of the 1999 Halifax Conference. Liner Shipping: What's next?, p. 204-220, 1999.

MURPHY, P.; DALEY, J. Investigating selection criteria for international freight forwarders. Transportation Journal, p. 29-36, Fall 1997.

NOTTEBOOM, T.; WINKELMANS, W. Reassessing public sector involvement in European seaports. International Journal of Maritime Economics, n. 3, p. 242-259, 2001.

cross ref

OECD - Organisation for Economic Co-operation and Development. Principles of corporate governance. Paris: OECD, 2004. Disponível em: 〈http://www.oecd.org/dataoecd/32/18/31557724.pdf〉. Acesso em: 13 abr. 2010.

OMC - Organização Mundial do Comércio. Site Institucional. Disponível em: 〈http://www.wto.org>. Acesso em: 05 nov. 2010.

RIBEIRO, J. L. D.; MILAN, G. S. Planejando e conduzindo entrevistas individuais. In: RIBEIRO, J. L. D.; MILAN, G. S. (eds.). Entrevistas individuais: teoria e aplicações. Porto Alegre: FEEng/UFRGS, 2004. cap. 1, p. 9-22.

SANTOS, C. H. S.; et al.. Eficiência da estratégia de produção: proposição de um modelo de avaliação. In: VIEIRA, G. B. B.; SANTOS, C. H. S. (org.). Logística e rede de valor. Volume 1. São Paulo: Aduaneiras, 2008, p. 41-64.

SKINNER, D.; TAGG, C. \& HOLLOWAY, J. Managers and research: the pros and cons of qualitative approaches. Management Learning, v. 31, n. 2, p. 163-179, 2000.

cross ref

SUYKENS, F.; Van De VOORDE, E. A quarter of a century of port management in Europe: objectives and tools. Maritime Policy and Management, n. 25, p. 251-261, 1998.

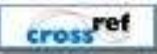

UNCTAD - United Nations Conference on Trade and Development. Strategic planning for port authorities. United Nations: Geneva, 1993. 
Van de VOORDE, E.; WINKELMANS, W. A general introduction to port competition and management. In: Port competitiveness: an economic and legal analysis of the factors determining the competitiveness of seaports. Proceedings... Antwerpen, De Boeck, p. 1-16, 2002.

VERGARA, S. C. Projetos e relatórios de pesquisa em administração. 11. ed. São Paulo: Atlas, 2009.

VIEIRA, G. B. B. Transporte internacional de cargas. 2. ed. São Paulo: Aduaneiras, 2003.

VIEIRA, G. B. B.; RODRIGUES, S. L. A. O nível de serviço de um consolidador de cargas marítimas sob a ótica dos usuários. Revista Produção On Line, v. 5, n. 2, Florianópolis, 2005.

VIEIRA, G. B. B.; PASA, G. S.; ARENHART, E. J. A atuação de um International Freight Forwarder pela ótica dos usuários In: Encontro Nacional de Engenharia de Produção, 28, 2008, Rio de Janeiro. Anais... Enegep, Rio de Janeiro, 2008.

VIEIRA, G. B. B. et al.. O posicionamento competitivo dos International Freight Forwarders pela ótica dos exportadores gaúchos In: ENCONTRO DA ASSOCIAÇÃO DOS PROGRAMAS DE PÓS-GRADUAÇÃO EM ADMINISTRAÇÃO, 31, 2007, Rio de Janeiro. Anais... ANPAD - EnANPAD, Rio de Janeiro, 2007.

WINKELMANS, W. One day conference on current trends and practices in the organisation, operation and management of ports and port terminals. Institute of Transport and Maritime Management Antwerp. University of Antwerp. Thessaloniki, Greece, 2008. Disponível em: <http://www.hermes.civil.auth.gr/pgtransport/ docs/Winkelmans_PORT_GOVERNANCE_and_SRM_2008.pdf>. Acesso em: 12 abr. 2010.

WOLCOTT, H. F. Transforming qualitative data: description, analysis, and interpretation. Thousand Oaks: Sage Publications, 1994.

YIN, R. K. Case study research: design and method. $2^{\text {nd }}$ edition. Sage Publications: Thousand Oaks, 1994.

\section{Dados dos autores:}

\section{Nome: Gabriel Sperandio Milan}

Filiação institucional: Universidade de Caxias do Sul (UCS)

Centro: Centro de Ciências da Administração

Função: Professor pesquisador ligado aos programas de Mestrado e Doutorado em Administração Endereço para correspondência: Rua: Francisco Getúlio Vargas, 1130 - PPGA / Bloco F - $4^{\circ}$ andar - Bairro: Jardim América - 95070-560 - Caxias do Sul - RS

Telefones para contato: (54) 3218.2100

e-mail:gsmilan@ucs.br

\section{Nome: Guilherme Bergamann Borges Vieira}

Filiação institucional: Universidade de Caxias do Sul (UCS)

Função: Professor pesquisador (UCS) e doutorando em Engenharia de Produção pela Universidade Federal do Rio Grande do Sul (UFRGS)

Endereço para correspondência: Rua: Francisco Getúlio Vargas, 1130 - PPGA / Bloco F - 4 andar

- Bairro: Jardim América - 95070-560 - Caxias do Sul - RS

Telefones para contato: (54) 3218.2100

e-mail: gbvieira@cpovo.net 
Enviado em: 19/04/2011

Aprovado em: 13/12/2011 